\title{
O PROCESSO EVOLUTIVO DO TRANSPORTE ESCOLAR RURAL BRASILEIRO NO MODO RODOVIÁRIO
}

\author{
The evolutionary process of the Brazilian Rural School Transportation in road \\ transport
}

\author{
Willer Luciano Carvalho', Poliana de Sousa Leite ${ }^{2}$, Heitor Pereira do Nascimento ${ }^{3}$
}

Recebido em 18 de julho de 2016; recebido para revisão em 11 de agosto de 2016; aceito em 10 de outubro de 2016; disponivel on-line em 17 de novembro de 2016.

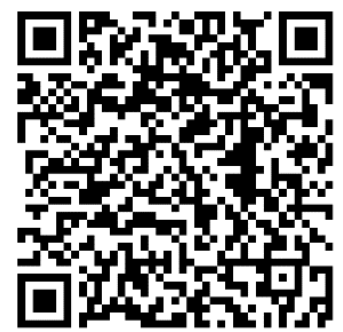

PALAVRAS CHAVE:

Transporte escolar rural; Caminho da escola; Transporte escolar; Planejamento de transporte; Avaliação em transporte.

\section{KEYWORDS: \\ Rural school; Transportation; Road to school; School transportation; Transport rating.}

\footnotetext{
* Contato com os autores:

${ }^{1}$ e-mail: willer_carvalho@ufg.br (W. L. Carvalho)

Professor Doutor da Universidade Federal de Goiás.

${ }^{2}$ e-mail: polianaleite@gmail.com (P. S. Leite)

Mestre, Arquiteta e Urbanista, SET.

3e-mail: hpnasci@ig.com.br (H. P. Nascimento)

Mestre, Gestor, ANTT.
}

RESUMO: Os estudantes brasileiros, especialmente os que residem em zonas rurais, enfrentam várias dificuldades para terem acesso à educação, como os longos trajetos entre a casa e a escola. O oferecimento do serviço de transporte escolar gratuito é fundamental nesse processo a fim de assegurar um direito constitucional. Diante disso, o Governo Federal criou o programa "Caminho da Escola", que tem como meta a renovação da frota, além de estudos, juntamente com universidades federais, para melhor conhecer a realidade desse serviço, e promover melhorias no sistema. Dessa forma, esse trabalho tem como objetivo avaliar a evolução do transporte escolar rural no Brasil a partir da implantação do programa Caminho da Escola e do desenvolvimento dos estudos a partir de 2005 pelo Fundo Nacional de Desenvolvimento da Educação - FNDE com o apoio de Universidades. Assim, foi realizada uma pesquisa de campo abrangendo todo o território brasileiro, coordenada pelo FNDE, e a Universidade Federal do Tocantins, onde foram pesquisados 450 municípios, permitindo caracterizar o transporte escolar rural do Brasil, e comparar os resultados encontrados com os obtidos no início dos estudos e antes da implantação do programa. Como resultado, foi observada melhoria no Transporte Escolar Rural no Brasil. Assim, o trabalho atinge o seu objetivo em mostrar o processo evolutivo desse serviço ao longo dos anos, apontando os efeitos das políticas públicas implementadas.

\begin{abstract}
Brazilian students, especially those living in rural areas face a number of difficulties to education access, such as long commutes between home and school. The offer of free school transport service is essential in this process to ensure a constitutional right. Thus, the Federal Government created the program "Road to School", which aims to fleet renewal, as well as studies, along with federal universities, to better understand the service reality, and improve the system. Thus, this study aims to assess the development of rural school transportation in Brazil since the implementation of the Road to School program and the development of studies from 2005 by the National Fund for Education Development - FNDE with the support of universities. Thus, a field survey covering the entire Brazilian territory was held, coordinated by the FNDE, and the Federal University of Tocantins, where they surveyed 450 municipalities, allowing characterize the rural school transportation in Brazil. Thus, the work reaches its goal to show the evolutionary process of this service over the years, indicating the effects of the implemented public policies.
\end{abstract}




\section{INTRODUÇÃO}

Os estudantes brasileiros, em especial os que residem em zonas rurais, enfrentam uma série de dificuldades para terem acesso à educação e se manterem nas escolas. As longas distâncias de caminhada, ou os longos trajetos dentro do serviço de transporte coletivo, trazem para as crianças desafios diários que por vezes as impedem de dar continuidade ao seu processo de aprendizagem. Por essas razões, o oferecimento do ensino público gratuito, muitas vezes, não é suficiente para permitir o acesso ou até mesmo para assegurar a permanência desse aluno na escola.

Foi pensando nessa realidade que o legislador constituinte atrelou ao dever de oferecer a educação, outras obrigações que se podem chamar de acessórias, mas que, na verdade, complementam o direito ao ensino público e por meio das quais se possibilita o acesso e a permanência do educando no ambiente escolar, como é o caso do serviço de transporte escolar rural gratuito (Feijó, 2007).

No artigo 208 da Constituição Brasileira, encontram-se as obrigações do Estado, no que se refere ao oferecimento do ensino público. Nesse sentido, a legislação brasileira prevê que compete aos estados e municípios o transporte escolar dos alunos da rede de ensino estadual e municipal, respectivamente (Brasil, 1998).

Estudos realizados pelo Fundo Nacional de Desenvolvimento da Educação, do Ministério da Educação do Brasil, em parceria com a Universidade de Brasília (UnB) - Centro de Formação de Recursos Humanos em Transportes (Ceftru), apontam que no Brasil mais de 4,8 milhões de estudantes da educação básica da rede pública que residem em área rural dependem de transporte para chegar à escola (FNDE, 2015).

Em função dessa dependência em relação ao serviço de transporte para garantir o acesso e a permanência das crianças nas escolas, o Governo Federal criou, no ano de 2007, o programa intitulado "Caminho da Escola". Este programa tem como objetivo promover a padronização dos veículos utilizados no transporte escolar rural no Brasil, bem como realizar a renovação da frota existente. O Programa Caminho da Escola foi subsidiado por uma série de estudos e pesquisas desenvolvidas em uma parceria do FNDE com Universidades Brasileiras.

Dessa forma, este trabalho tem como objetivo realizar uma avaliação da evolução por que passou o setor do transporte escolar rural no Brasil a partir da implantação do programa Caminho da Escola e dos estudos desenvolvidos pelo FNDE e as Universidades. Para tal, foi realizada uma pesquisa de campo de âmbito nacional, coordenada pelo FNDE, em parceria com a Universidade Federal do Tocantins.

A pesquisa levantou dados em mais de 450 municípios distribuídos em todos os estados da federação, e percorreu mais de dez mil rotas do transporte escolar rural, o que permitiu traçar um novo retrato da prestação desse serviço. Assim, esse novo retrato foi comparado com o diagnóstico realizado em outra pesquisa desenvolvida no ano de 2006, também coordenada pelo FNDE, em que se fez uma primeira caracterização do transporte escolar, a fim de avaliar o impacto do programa Caminho da Escola no serviço de transporte escolar rural no Brasil.

\section{A EDUCAÇÃO DO CAMPO NO BRASIL}

Ao longo de sua história, o Brasil não deu a devida importância às questões sociais do campo, inclusive à educação rural. Apesar de ser um país formado a partir de uma cultura agrária, os interesses relacionados à educação estavam focados nas classes médias emergentes, relegando a população rural a uma situação de abandono.

Assim, o surgimento da educação rural no Brasil só se deu no século XX, em função do intenso processo migratório ocorrido nesse período, com as pessoas deixando as áreas rurais em busca das regiões urbanas. Com isso, a educação rural configurou-se como um dos instrumentos para conter a migração no sentido rural-urbano (FNDE, 2015a).

Foi apenas na Constituição de 1988 $\mathrm{CF} / 88$, em seu artigo 208, que o acesso ao ensino obrigatório e gratuito como direito público subjetivo foi considerado (SILVA et al, 2005). A Constituição 
Brasileira de 1988 estabelece, no art. 60, que a educação constitui direito social a ser garantido a todas as crianças e adolescentes, residentes em áreas urbanas ou rurais, de forma a permitir-lhes iguais condições e oportunidades no exercício de seu papel como cidadãos (BRASIL, 1998).

Uma das políticas de destaque adotada para a educação da área rural no Brasil foi a que tratou do processo de nucleação do sistema educacional brasileiro. O processo de nucleação consiste em agrupar pequenas escolas e classes (as chamadas escolas isoladas das áreas rurais) em um prédio central, geralmente situado na área urbana, ou em áreas mais centrais localizadas entre as fazendas e as comunidades (SALES, 2007).

O processo de nucleação foi desenvolvido buscando-se a melhoria do sistema educacional e a igualdade de condições para a escola do campo frente à urbana. Entretanto, esse processo de nucleação foi e é criticado, uma vez que retira o aluno da área rural, e além disso, o processo de nucleação tornou o aluno das áreas rurais ainda mais dependente do transporte escolar para acessar as escolas, em função da distância que as unidades de ensino passaram a estar perante seus alunos.

\subsection{NÚMEROS DA EDUCAÇÃO DO CAMPO NO BRASIL}

De acordo com os dados do Ministério da Educação e do INEP existem no Brasil mais de 50 milhões de alunos na educação básica. Desses alunos, $88 \%$ estão matriculados em escolas da área urbana e apenas $12 \%$ em escolas rurais, o que mostra a grande concentração das unidades de ensino nos centros urbanos, tornando o transporte dos alunos fator fundamental para a garantia do acesso à educação (MEC/INEP, 2014).

Em relação às matrículas, verifica-se ainda a forte dependência de serviços públicos por parte dos estudantes do ensino básico, pois mais de $99 \%$ dos alunos da educação básica da área rural estavam, em 2014, matriculados em escolas públicas. $O$ índice de analfabetismo da população com 10 anos ou mais, na zona rural, correspondeu a $21 \%$ em 2008 , enquanto no meio urbano essa taxa foi de $8 \%$ (PNAD, 2008). No entanto, houve uma redução na taxa de analfabetismo entre os anos de
1991 e 2008, principalmente no campo, mas os resultados ainda apontam para grandes discrepâncias entre cidade e campo (MEC, 2007).

Com relação à rede de ensino, no início do século XX, havia programas voltados para a construção de escolas no meio rural, as chamadas escolas isoladas (PEGORETTI, 2005). Essas escolas surgiram para tentar conter o êxodo rural, por meio da fixação do homem no campo, pela difusão do ensino. Todavia, a iniciativa não teve êxito devido à oferta insuficiente de escolas; ao porte dos prédios, que eram pequenos e malconservados; à má qualidade de ensino; e à má remuneração de professores, os quais tinham baixo nível de formação e careciam de apoio pedagógico e administrativo (VASCONCELLOS, 1992). Além desses problemas, destacaram-se ainda a dificuldade de realizar serviços de supervisão em face do isolamento geográfico, a existência de salas multisseriadas com ensino restrito até a $4 \underline{a}$ série e o alto índice de evasão escolar (GEIPOT, 1995).

Tais problemas levaram à falência das chamadas escolas isoladas, que foram substituídas por escolas nas áreas urbanas. Surge assim, o processo de nucleação das escolas, que foram agrupadas em áreas urbanas ou áreas rurais mais desenvolvidas, nas quais havia demanda suficiente para sustentá-las. No entanto, tais aspectos geraram maior demanda de transporte para garantir o acesso dos estudantes às unidades de ensino, bem como, trouxeram problemas no deslocamento desses alunos, que passaram a permanecer muito tempo dentro dos veículos.

Diante da crescente dependência do transporte escolar gratuito, fornecido pelos municípios, que os alunos residentes nas áreas rurais possuem, o Governo Federal vem tomando medidas com o intuito de auxiliar na prestação desse serviço, além de buscar garantir maiores conforto e segurança para seu alunado. Dessa forma, surgiu em 2007, o programa Caminho da Escola, com o objetivo de padronizar os veículos utilizados na prestação do serviço, bem como promover uma renovação dessa frota (FNDE, 2015a). 


\section{A EDUCAÇÃO DO CAMPO NO BRASIL}

O programa Caminho da Escola foi criado no ano de 2007 a partir da Resolução no 3, do Conselho Deliberativo do FNDE, de 28 de março de 2007. Sua criação teve como objetivo promover a renovação da frota de veículos utilizados para a prestação do serviço de transporte escolar rural no Brasil, além de melhorar as condições de segurança e qualidade do transporte dos estudantes, e contribuir para a redução da evasão escolar (Brasil, 2007). Dentre os principais objetivos do programa Caminho da Escola, apresentados no Decreto no 6.768 , de 10 de fevereiro de 2009, pode-se citar (Brasil, 2009):

- renovar a frota de veículos escolares na zona rural;

- garantir a qualidade e segurança do transporte escolar na zona rural;

- $\quad$ garantir o acesso e a permanência dos estudantes da zona rural nas escolas;

- reduzir a evasão escolar;

- reduzir o preço de aquisição dos veículos.

O FNDE considera que os objetivos traçados serão atingidos a partir da disponibilidade de veículos padronizados, com preços de aquisição mais acessíveis por parte dos municípios, mais transparência no processo, veículos mais confortáveis e seguros, garantindo assim o acesso e a permanência na escola dos estudantes matriculados na educação básica da zona rural das redes estaduais e municipais (FNDE, 2015a).

Assim, o FNDE oferece aos municípios e aos usuários do transporte escolar rural no Brasil, veículos padronizados e com especificações exclusivas, próprias para o transporte de estudantes, e adequado às condições de trafegabilidade das vias das zonas rurais brasileiras (FNDE, 2015a).

A aquisição dos veículos por parte dos municípios e estados dentro do programa é realizado a partir de um pregão eletrônico de registro de preços realizado pelo próprio FNDE, considerando as especificações técnicas exigidas dentro do programa. Existindo três formas distintas para que estados e municípios participem do programa, sendo eles (Brasil, 2009):

- recursos orçamentários do

Ministério da Educação

- linha especial de crédito a ser concedida pelo Banco Nacional de Desenvolvimento econômico e Social - BNDES

- recursos próprios dos entes federativos que aderirem ao Programa Caminho da Escola.

Dentro do processo de padronização de veículo foram realizados estudos em parceria com a universidade para definir as especificações dos veículos para que o mesmo atendesse às especificidades do meio rural e das vias onde deveria trafegar.

Assim, foram definidos modelos de ônibus (Figura 1), lancha (Figura 2) e bicicletas (Figura 3), todos testados em estudos realizados em parceria com a Universidade de Brasília (UnB). Para o caso do ônibus, a avaliação final de entrega dos diferentes modelos desenvolvidos é realizada com uma parceria estabelecida com o Instituto Nacional de Metrologia, Qualidade e Tecnologia - INMETRO. No caso das lanchas escolares, essa parceria foi estabelecida com a Marinha do Brasil e universidades federais (FNDE, 2015a).
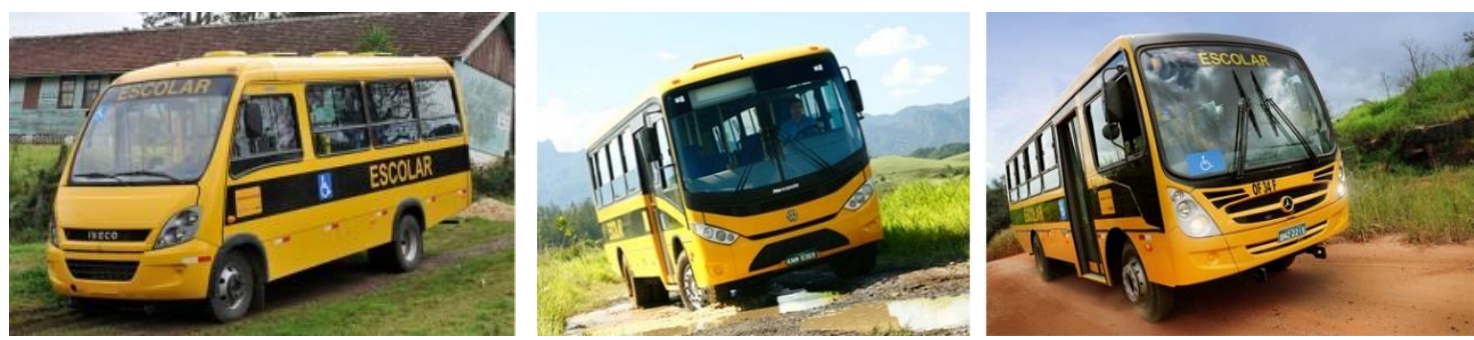

FIGURA 1: Imagem dos modelos de ônibus desenvolvidos. FONTE: CAMINHO DA ESCOLA (2015) 


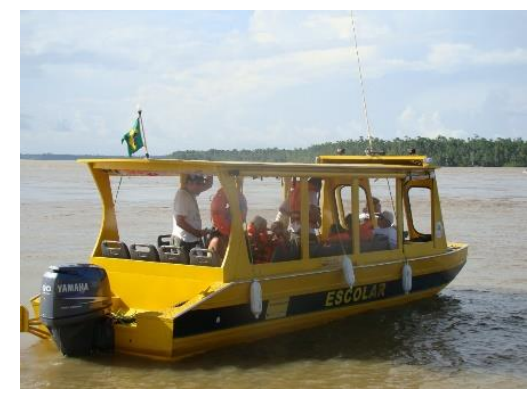

FIGURA 2: Imagem da Lancha Escolar. FONTE: Autoria própria

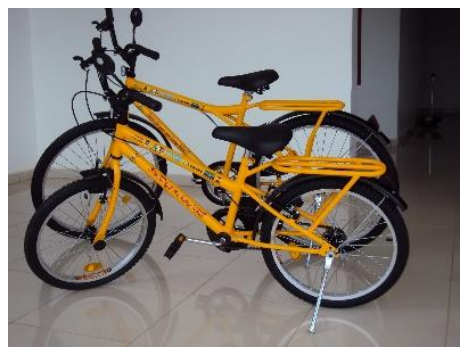

FIGURA 3: Imagem dos modelos de bicicleta desenvolvidos.

FONTE: Autoria própria

Desde sua criação o programa Caminho da Escola tem obtido sucesso e atingido seus objetivos. Tal sucesso pode ser observado pelos números atingidos desde 2008 até junho de 2015 (FNDE, 2015b) no que se refere aos veículos já distribuídos ao longo do país.

\footnotetext{
- $\quad 36.186$ ônibus escolar rural;

- 176.988 bicicletas;

- 933 lanchas
}

\section{OS ESTUDOS DESENVOLVIDOS PELO FNDE EM PARCERIA COM UNIVERSIDADES}

O Fundo Nacional de Desenvolvimento da Educação - FNDE, uma autarquia federal ligada ao Ministério da Educação do Brasil vem desenvolvendo parcerias com universidades brasileiras desde o final do ano de 2005, para entender e propor soluções para a melhoria do transporte escolar rural no país.

Ao longo dessa parceria duas universidades desenvolveram estudos específicos para o transporte escolar rural, sendo elas a Universidade de Brasília, e a Universidade Federal do Tocantins. Assim, uma série de estudos e produtos foi gerada ao longo desses anos, e os mesmos podem ser visualizados na Figura 4.

Nos anos de 2005 e 2006 foi realizada uma pesquisa para a caracterização do Transporte Escolar Rural - TER, na qual foram visitados 17 municípios das cinco regiões do país, além de uma pesquisa na internet que contou com a participação de 2277 municípios, que correspondem a 41\% dos municípios Brasileiros. Nessa pesquisa foram levantados dados que permitiram caracterizar e melhor entender o estado do Transporte Escola Rural no Brasil.

Em 2007, em função dos resultados obtidos com a caracterização, foram desenvolvidas metodologias para a caracterização da demanda, e para o repasse do recurso do governo federal dentro do Programa Nacional de Auxílio ao Transporte Escolar - PNATE, além de estudo dos grupos minoritários. Dentre os grupos minoritários foram visitadas comunidades indígenas, ribeirinhos, assentamentos rurais e comunidades quilombolas (comunidades remanescentes de escravos ou suas gerações atuais).

Em 2008 foi desenvolvido o diagnóstico do TER, além de uma série de manuais e metodologias. Assim, foram desenvolvidos manuais de planejamento e regulação do TER, para auxiliar os municípios na gestão do serviço, e a metodologia para a estimativa do custo do transporte escolar, até então inexistente. Além disso, nesse ano surge o primeiro modelo do Ônibus Rural Escolar do Brasil, uma versão ainda preliminar. 


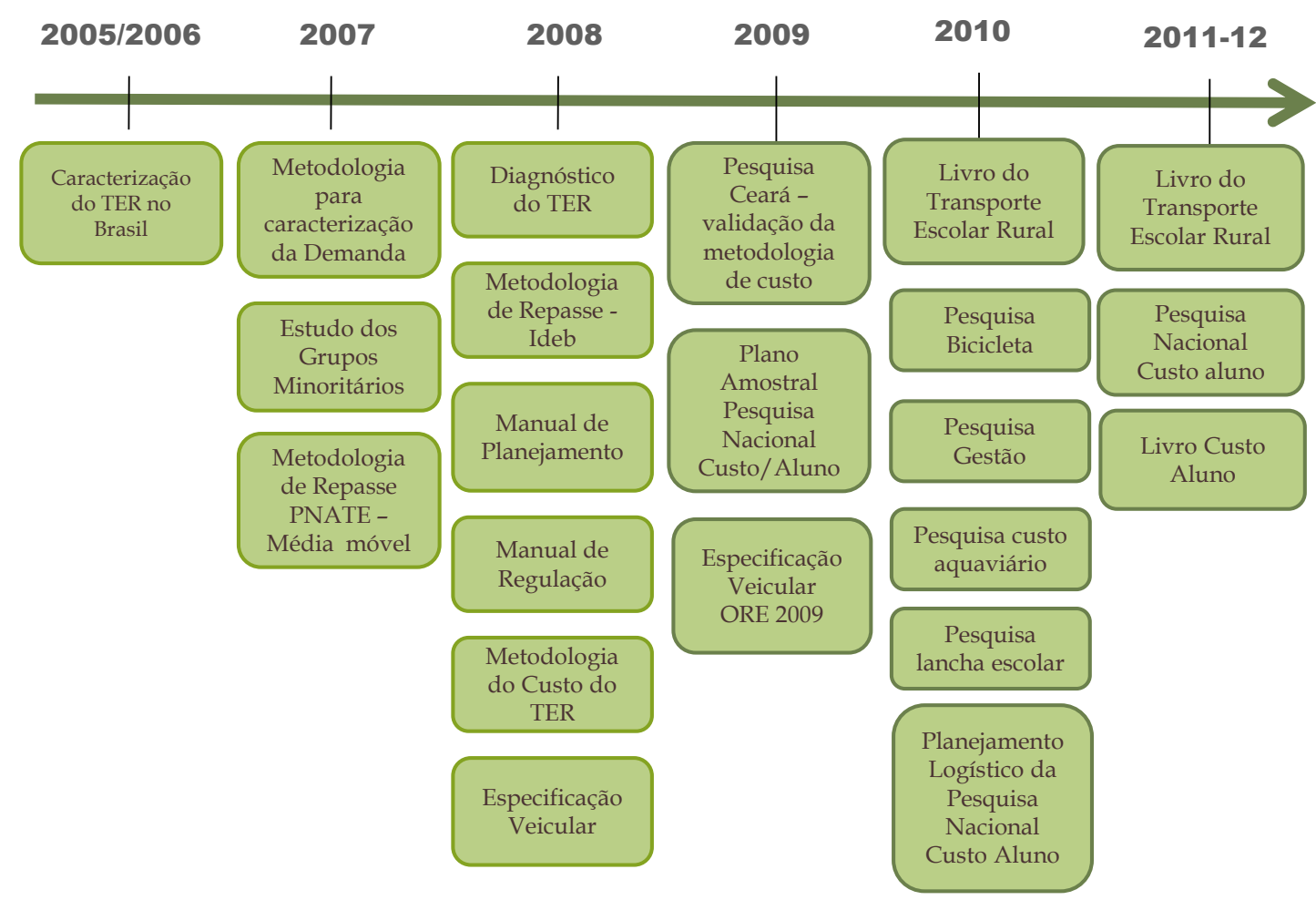

FIGURA 4: Histórico dos Estudos Desenvolvidos.

FONTE: Autoria própria

Em 2009 a metodologia para estimativa do custo do transporte escolar rural foi validade em uma pesquisa de campo, desenvolvida no estado do Ceará, em 34 municípios. Com o retorno positivo da aplicação da metodologia, foi desenvolvido o plano amostral para realizar a estimativa nacional do custo do TER. Nesse mesmo ano ocorre o desenvolvimento final do Ônibus Rural Escolar do Brasil, com o desenvolvimento de quatro protótipos os quais foram colocados em teste nas diferentes regiões do país, e percorreram mais de 50 mil quilômetros para avaliação.

No ano de 2010 destacam-se o desenvolvimento de bicicletas para o transporte escolar, sendo uma de aro 20 e outra coma aro 22, e as mesmas foram testadas pelos próprios estudantes em 25 municípios da federação, a pesquisa para testar a lancha escolar desenvolvida pela Marinha do Brasil, na qual as lanchas foram testadas ao longo da bacia amazônica, e toda a preparação logística para a pesquisa nacional custo aluno.

Nos anos de 2011 e 2012 foi realizado o levantamento de dados para a estimativa do custo do transporte escolar rural no Brasil. Nesse levantamento foram coletados dados em 450 municípios e o Distrito Federal, e foram percorridas mais de 13 mil rotas do transporte escolar rural. Os municípios pertencem a todos os estados da Federação, sendo escolhidos a partir de uma amostragem probabilística.

\section{EVOLUÇÃO DO TRANSPORTE ESCOLAR NO BRASIL}

Como pode ser observado, os projetos de pesquisa financiados pelo FNDE e executados pelas universidades a partir do ano de 2005, geraram uma série de informações e produtos, visando promover uma melhoria no estado do transporte escolar rural no Brasil. A fim de verificar a efetividade dessas ações foi realizada uma análise comparativa entre duas das pesquisas desenvolvidas, a realizada em 2005/2006, período anterior à implementação do Programa Caminho da Escola, com a realizada em 2011/2012, correspondendo a cinco anos do programa e sete anos de estudos. É importante salientar que os autores desse artigo participaram de pelo menos uma das pesquisas citadas.

O estudo realizado ano de 2005/2006 foi uma parceria do FNDE com a Universidade de 
Brasília - UnB. Esse estudo foi desenvolvido com a aplicação de um questionário disponibilizado na Internet para que os gestores municipais pudessem respondê-lo, e foram visitados 17 municípios. Dos 5.544 municípios existentes no território brasileiro 2.277 (41\%) responderam o questionário em sua totalidade (FNDE/UnB, 2007).

Nos anos de 2011 e 2012 o FNDE, em parceria com a Universidade Federal do Tocantins UFT, desenvolveu um estudo abrangendo todo o território brasileiro para realizar a estimativa do custo por aluno do transporte escolar rural, nas diferentes regiões do país.

$\mathrm{Na}$ pesquisa realizada no ano de 2012 foram visitados 450 municípios mais o Distrito Federal, correspondendo a uma amostra com $90 \%$ de nível de confiança e erro de $10 \%$. Foram pesquisados municípios em todas as regiões do país e em todos os Estados da Federação.

\subsection{TIPIFICAÇÃO DOS VEÍCULOS}

Em função dos números apresentados já atingidos pelo programa Caminho da Escola, verifica-se um aumento da utilização dos microônibus, especificamente projetados para a área rural brasileira, sendo utilizados pelos municípios. Isso pode ser comprovado quando comparamos os dados da tipificação dos veículos em 2006 como os obtidos em 2012 (Figuras 5a e 5b).

Assim, dos dados apresentados na Figura 5 pode-se inferir que no que diz respeito à

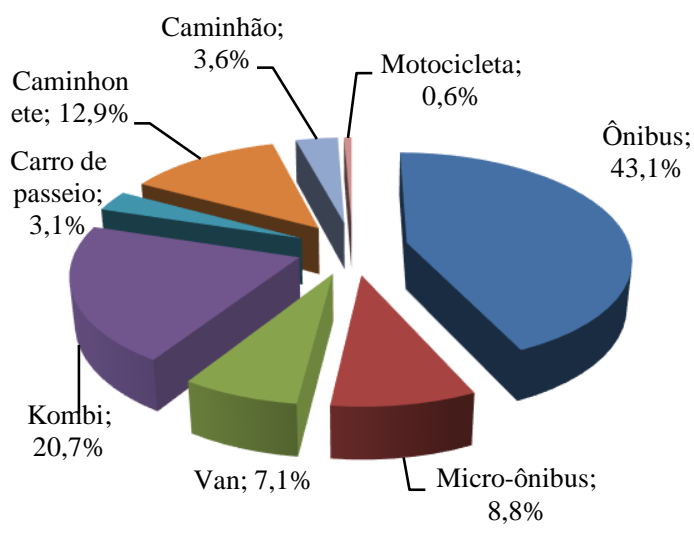

FIGURA 5a: Veículos Rodoviários - 2006. FONTE: Adaptado de FNDE/UnB, 2007. composição da frota rodoviária utilizada para a prestação do serviço do TER, nas diferentes regiões do Brasil, tanto no ano de 2006 como em 2012, o ônibus correspondeu à maior parcela $(43,1 \%$ no ano de 2006 e 36,6\% em 2012).

Quando comparado o conjunto de dados verifica-se uma pequena mudança na composição da frota entre os dois anos analisados. Houve um aumento de $6,7 \%$ no uso de micro-ônibus e uma redução de $1,7 \%$ na utilização de caminhonete e caminhão, além de reduções no uso de motocicletas e caminhonete. Tais aspectos apontam para uma melhoria na qualidade da prestação do serviço, uma vez que está ocorrendo a substituição de veículos impróprios para o transporte dos alunos, para veículos mais adequados. Indicando resultado da política adotada.

\subsection{IDADE DOS VEÍCULOS}

Outro aspecto que mostra os resultados já alcançados a partir dos estudos e da implementação do programa Caminho da Escola pelo Governo Federal está na avaliação da idade dos veículos utilizados para o transporte escolar rural. Os resultados apontam para uma redução de cerca de $20 \%$ na idade média para todo o país, passando de 16 anos para 13 anos de idade. Novamente percebese que o programa de renovação da frota tem obtido resultados satisfatórios (Figura 4).

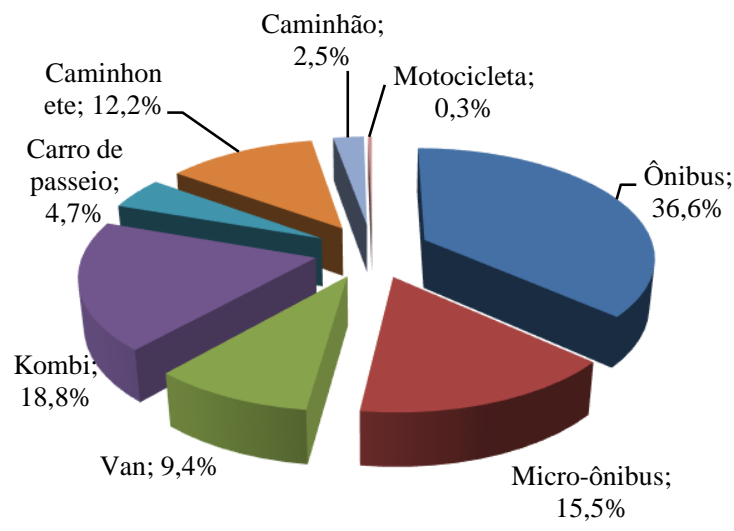

FIGURA 5b: Veículos Rodoviários - 2012 FONTE: Autoria própria. 


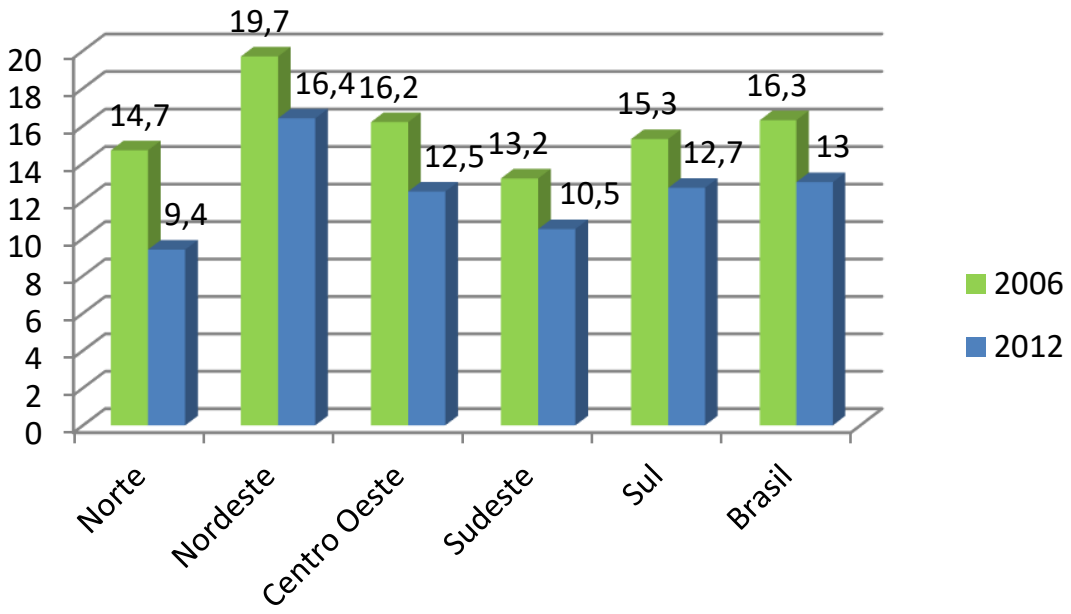

FIGURA 4: Idade média da frota por Estado e Brasil.

FONTE: Autoria própria

Percebe-se em que todas as regiões sofreram redução na idade média da frota, onde o Nordeste e o Sul foram as regiões que tiverem a menor redução, cerca de $17 \%$, enquanto que a Região Norte teve a maior redução da idade da frota, chegando a $36 \%$. Como em todas as regiões observou-se uma redução considerável na idade da frota, verifica-se que o programa realmente tem atingido o objetivo de reduzir a idade da frota no território brasileiro, e ainda que essa redução ocorre em todos as regiões do país, mostrando uma boa abrangência dentro do território brasileiro.

\subsection{TAXA DE OCUPAÇÃO DOS VEÍCULOS}

No que se refere à taxa de ocupação dos veículos nota-se uma melhora significativa nas rotas rodoviárias pesquisadas. Sabendo-se que a taxa não deve ultrapassar o valor de 1 , observou-se que a taxa de ocupação média dos veículos rodoviários nos estados variou entre 0,76 , no Rio Grande do Sul a 1,19 no Piauí, ficando um valor médio para o Brasil equivalente a 1 , ou seja, de modo geral, a ocupação dos veículos do transporte escolar rural fica dentro de sua capacidade na média nacional. Esse é um quadro bem diferente do encontrado em 2006, quando a média foi de 2,7 .

\subsection{QUILOMETRAGEM PERCORRIDA NAS ROTAS}

As quilometragens percorridas nas rotas rodoviárias são extensas, fazendo com que as crianças tenham que permanecer por horas dentro do veículo. Na pesquisa de 2012 em média, as rotas apresentam no seu trajeto completo (ida e volta) $73,9 \mathrm{~km}$ de extensão. No entanto foi observada rota com apenas $2 \mathrm{~km}$ de extensão e a maior rota verificada tinha $371,58 \mathrm{~km}$. Na rota mais extensa os alunos permaneciam mais de quatro horas no trajeto entre a casa e a escola.

Ao se analisar a distribuição das rotas por faixa de quilometragem verificou-se a existência de rotas com extensão inferior a $5 \mathrm{~km}$, e as maiores rotas eram superiores a $350 \mathrm{~km}$. No entanto, observou-se que mais de $72 \%$ das rotas encontramse entre 10 e 70 quilômetros de percurso total (ida e volta).

Tal aspecto não sofreu variação quando comparado com os dados de 2006, que também encontrou rotas com grandes extensões e com alunos tendo que permanecer muitas horas dentro dos veículos para acessarem as escolas.

\section{CONCLUSÕES}

Os resultados apresentados nesse trabalho tratam da comparação de duas pesquisas realizadas pelo FNDE em parceria com universidades, e que tiveram características distintas. A primeira pesquisa de caracterização do transporte escolar rural, realizada pela UnB em 2006, tratou-se de uma pesquisa realizada via web, com dados coletados de forma declaratória, com a participação de mais de 2 mil municípios. Já na 
segunda pesquisa, realizada em 2012, os dados foram coletados em campo, com registros sistemáticos de todas as informações colhidas, no entanto apresentou uma amostragem mais reduzida. Entretanto ambas as pesquisas foram realizadas com amostras probabilísticas permitindo, portanto, e elaboração de inferências estatísticas.

Mesmo com as diferenças citadas, os resultados mostram-se de grande relevância e apontam para um melhora na prestação do serviço do transporte escolar rural no Brasil ao longo dos 5 anos que separam as pesquisas. Houve a redução de $1,7 \%$ no uso de veículos impróprios, como caminhonetes e caminhões, e um aumento de mais de $6 \%$ no uso de micro-ônibus, que é o veículo mais barato oferecido dentro do programa Caminho da Escola.

Além da mudança no tipo de veículo utilizado, verifica-se uma redução na idade média da frota utilizada, que passou de 16,3 em 2006 para 13 anos em 2012. Tais fatos mostram uma substituição dos veículos antigos e impróprios para o serviço de transporte escolar por veículos mais adequados e novos. Isso garante a prestação de um serviço com mais qualidade, conforto e segurança para os alunos.

Assim, verifica-se ter sido de grande sucesso a parceria estabelecida entre uma autarquia do governo federal e as universidades, que gerou estudos, manuais e produtos que passaram a nortear parte das políticas públicas e auxiliaram no processo de desenvolvimento do setor.

No entanto, como esse serviço foi, por muito tempo negligenciado pelo poder público brasileiro, a situação de precariedade é grande, e as melhorias alcançadas ainda não conseguem qualificar o transporte escolar rural no Brasil como um serviço de qualidade. As melhorias observadas estão ocorrendo de uma forma lenta, porém gradual, e ainda existem grandes desafios, como a melhoria do sistema viário, e a redução do tempo de deslocamento dos alunos no trajeto de sua casa para a escola.

Assim, é importante que se dê
continuidade ao processo de renovação e
substituição da frota hoje em operação,

principalmente no que se refere aos veículos impróprios à prestação desse serviço vital para as comunidades rurais, o contínuo aprimoramento dos veículos para que possam atender as mais diversas particularidades encontradas no meio rural do Brasil, e aprimorar as políticas públicas para garantir não só o acesso à escola, mas que esse acesso seja facilitado, com a maior qualidade e conforto possível, e com menores tempos de deslocamento.

Com isso, este trabalho atinge seu objetivo, no que se refere a fazer uma avaliação do processo evolutivo por que tem passado o transporte escolar rural nos últimos anos, principalmente aqueles relacionados com políticas públicas desenvolvidas para o setor, mostrando que o programa Caminho da Escola teve efeitos positivos na requalificação da frota utilizada no setor, melhorando a qualidade da prestação desse serviço no Brasil.

\section{AGRADECIMENTOS}

Os autores agradecem ao apoio dado pelo Fundo Nacional de Desenvolvimento da Educação e a todos os pesquisadores e colaboradores que participaram do levantamento de dados dentro das pesquisas desenvolvidas em parceria do FNDE com a Universidade de Brasília, a Universidade Federal do Tocantins e a Fundação de Apoio Científico e Tecnológico do Tocantins.

\section{REFERÊNCIAS BIBLIOGRÁFICAS}

BRASIL. Constituição (1988). Constituição da República Federativa do Brasil. Brasília, DF: Senado, 1988.

BRASIL. Resolução/FNDE/CD/no 03, de 28 de março de 2007. Cria o Programa Caminho da Escola e estabelece as diretrizes e orientações para que os Municípios, Estados e o Distrito Federal possam buscar financiamento junto ao Banco de Desenvolvimento Social e Econômico BNDES para aquisição de ônibus e embarcações enquadrados no Programa, no âmbito da Educação Básica - FNDE, Brasília, 2007.

BRASIL. Decreto no 6.768, de 10 de fevereiro de 2009. Disciplina o Programa Caminho da Escola. Presidência da República, Brasília - DF.

CAMINHO DA ESCOLA, 2015. Programa Caminho da Escola do Governo Federal. Página da Web < 
http://www.caminhodaescola.com.br/> acessada em 08/07/2015.

FEIJÓ, P. C. B. (2007) Transporte escolar: a obrigação do poder público municipal no desenvolvimento do programa. Aspectos jurídicos relevantes. Jus Navigandi, ano 11, n. 1259, Teresina.

FNDE/UnB (2007). Projeto: Transporte Escolar Rural Volume III - Tomo I - Caracterização do Transporte Escolar nos Municípios Visitados. Centro de Formação de Recursos Humanos, da Universidade de Brasília e Fundo Nacional de Desenvolvimento da Educação.

FNDE/UnB (2008). Diagnóstico do Transporte Escolar Rural - Volume I. Centro de Formação de Recursos Humanos da Universidade de Brasília e Fundo Nacional de Desenvolvimento da Educação.

FNDE, 2015a. Fundo Nacional de Desenvolvimento da Educação. Página da web <http://www.fnde.gov.br/programas/caminho-daescola/caminho-da-escola-apresentacao> acessada em, 07/07/2015.

FNDE, 2015b. Número de veículos já disponibilizados a partir do programa Caminho da Escola. Consulta realizada com técnicos do FNDE em 17 de junho de 2015.

GEIPOT (1995). Avaliação Preliminar do Transporte Rural - Destaque para o Segmento Escolar. Brasília. Empresa Brasileira de Planejamento de Transportes, 1995.

HOWLEY, C. B.; HOWLEY, A. A.; SHAMBLEN, S. (2001). The Experience of Rural School Bus Rides. Annual meeting of the American Educational Research Association, Seattle, Washington, April 10, 2001

MEC (2007). Educação do Campo: diferenças mudando paradigmas. MEC, Cadernos Secad 2, Brasília, DF, 2007.

MEC/INEP (2007). Censo Escolar: Sinopse Estatística da Educação Básica - 2007. Ministério da Educação - MEC e Instituto Nacional de Estudos e Pesquisas Educacionais Anísio Teixeira (Inep), 2007.

MEC/INEP (2014). Censo Escolar: Sinopse Estatística da Educação Básica - 2013. Ministério da Educação - MEC e Instituto Nacional de Estudos e Pesquisas Educacionais Anísio Teixeira (Inep), 2014.

PEGORETTI, M. S. (2005). Definição de um Indicador para Avaliar a Acessibilidade dos Alunos da Zona Rural às Escolas da Zona Urbana. Dissertação de Mestrado. UFScar. São Carlos - SP, 2005.

PNAD (2008) - Pesquisa Nacional por Amostra de Domicílio. Instituto Brasileiro de Geografia e Estatística IBGE, (2008)

VASCONCELLOS, E. A. (1992). População Rural e Acesso à Educação no Estado de São Paulo: análise da política pública. Tese de Doutorado em Ciência Política. USP, SP, 1992. 